\title{
Multi-Organizational Multi-Stakeholder Collaboration Systems: An Exploratory Research Study of Design Concerns in Healthcare
}

\author{
Fangjian Gao \\ University of Cologne, \\ DE \\ gao@wiso.uni-koeln.de
}

\author{
Scott Thiebes \\ Karlsruhe Institute of \\ Technology, DE \\ scott.thiebes@kit.edu
}

\author{
Ali Sunyaev \\ Karlsruhe Institute of \\ Technology, DE \\ sunyaev@kit.edu
}

\begin{abstract}
Much Collaboration Engineering research focuses on collaboration systems for teams of five to fifty members. That research can also inform large-scale multi-organizational multi-stakeholder (MO-MS) collaborations such as disaster relief, joint ventures, and healthcare. These larger contexts, though, present design concerns beyond those for smaller teams, and not all these concerns are self-evident. This paper explores the design concerns for IT-supported MO-MS collaboration. We selected the healthcare industry as the first exemplar domain for this inquiry mainly because research shows high potential benefits from, and substantial challenges to implementing systems for collaborative healthcare. We draw on an extensive literature review, and 50 semi-structured interviews with experts to discover and validate collaboration challenges presented by in-house and cloud-based IT services for healthcare. We derive an eleven-class typology of design concerns related to MO-MS collaboration, and derive requirements-elicitation design questions for each class. To demonstrate its utility, we draw on exploratory findings to elaborate the generalizable typology with design probes specific to healthcare collaboration systems.
\end{abstract}

\section{Introduction}

To date, the technical focus of Collaboration Engineering research has been collaboration systems for teams, typically ranging in size from five to fifty members. That research can also inform collaboration systems for large-scale multi-organizational multistakeholder (MO-MS) contexts such as disaster relief, joint ventures, public administration, and healthcare. These larger contexts, however, present design concerns beyond those for team collaboration, and not all those concerns are self-evident. This paper investigates design concerns for large-scale ITsupported MO-MS collaboration.

We selected the healthcare industry as the first exemplar domain for this exploration because healthcare faces several global challenges, and there is high potential for collaborative healthcare to mitigate those challenges. Global demand for healthcare is rising as incidents of acute and chronic diseases are accelerating, and populations are aging [1]. As a result, demands for healthcare services are expected to increase by more than $130 \%$ within the next 25 years [2]. Meanwhile, dwindling per-capita medical resources and shortages of medicines and healthcare professionals make it increasingly difficult for healthcare organizations such as hospitals and clinics to deliver appropriate levels of service [3, 4].

Collaboration in healthcare (e.g., for medical diagnosis, treatment, case management), supported by appropriate IT, can help to mitigate these challenges. Collaboration in healthcare is associated with improved health outcomes in situations where resources are strained [5]. Researchers identify three core infrastructure needs for healthcare collaboration, i.e. to coordinate collaborators' cooperative activities [6], to exchange structured data [7], and to support collaborators' communication for joint reasoning [8]. Health information systems that afford those capabilities are associated with, for instance, reduced preventable adverse drug reactions [9], decreased duplication of effort [10], and reduced waste of healthcare resources [11].

In many healthcare organizations, though, existing health information systems are not well-suited to healthcare collaboration [12]. A number of systems suffer multiple deficiencies, such as a) inadequate support for the various healthcare roles (e.g., patients, doctors, insurance companies, pharmacists) [12], b) high cognitive overload associated with the exchange of high-volume patient data [13], and c) delayed or incomplete communication among collaborators [14]. These insufficiencies impede collaboration, which fosters medical errors (e.g., misunderstanding caused by incomplete communication) that degrade healthcare and put patients at risk [6]. Such challenges seem to be common across MO-MS domains. It would therefore be useful to answer this research question: What are the design concerns for collaborative health information systems, and which of those aspects can be generalized across MO-MS contexts? 
In this paper, we draw on an extensive literature review, and on 50 semi-structured interviews with experts to discover and validate collaboration challenges presented by in-house and cloud-based IT services for healthcare. From the findings, we derive a generalizable typology comprising eleven classes of design concerns and design questions related to MOMS collaboration. To demonstrate the utility of the typology, we analyzed the design questions to determine which, if any, could be elaborated with domain-specific cues to foster even more-complete requirements elicitation in a given domain. We drew on the exploratory findings to create an instance of the generalizable typology elaborated with requirementselicitation prompts specific to the healthcare domain.

\section{Research Methods}

We conducted a two-year Design Science Research study using the disciplines for Exploratory Research [15] to discover and describe design concerns for MOMS collaboration, and to formalize them into a generalizable design tool for practitioners and researchers.

We investigated both in-house and cloudcomputing services (CCSs) because an increasing number of healthcare organizations (up to $82 \%$ ) now outsource to complement and improve their in-house IT [16], and CC is becoming their preferred form of outsourcing [17]. Further, many current CCS offerings in healthcare support some degree of collaboration $[18,23]$. Including $\mathrm{CC}$ could increase the comprehensiveness of our findings.

We began with an extensive review of the Information Systems, Computer Science, and Medical Informatics literatures drawn from several sources i.e., ACM Digital Library, AISeL, EBSCOhost, Emerald Insight, IEEE Xplore Digital Library, Proquest, PubMed, and ScienceDirect. We identified 6,609 potentially relevant articles, and screened them for content relevant to IT-supported collaboration in healthcare that is based on in-house IT or CCSs. This produced a final list of 100 relevant articles. From these articles, we abstracted six categories of design concerns. A more detailed description of the literature review is available on request.

We then conducted two rounds of expert interviews. The first round focused on capabilities of CCSs in healthcare that support collaborative activities. The interviewees came from healthcare organizations that consumed CCSs, and IT vendors that provided CCSs in China $(\mathrm{N}=12)$ and Germany $(\mathrm{N}=12)$, as we had access to experts in both countries. The interviews were conducted between Dec. 2014 and Nov. 2015. They had an average duration of 51 minutes. We recorded and transcribed all interviews.

The first-round interviews asked the experts to enumerate all CCSs in healthcare with which they were familiar, including, but not limited to those related to their own organizations. Interviewees were then asked to describe the purpose of each CCS, and the key capabilities of each, with special attention to those targeting collaboration in healthcare.

After 24 interviews, we reached conceptual saturation (i.e., the last few interviews revealed no new concepts) [15], so we ended the first round. We analyzed the interview transcripts and extracted, aggregated, and classified design concerns for collaboration systems in healthcare, and thereby four additional categories of design concerns that we had not discovered in the literature.

We then conducted a second round of interviews to validate results from the literature review and the first round of interviews, and, if possible, to identify further categories of design concerns. Interviewees in the second round were not only health IT experts but also clinical medical professionals who are regular users of health information systems for collaboration. Nine of the interviewees in the second round came from China and 17 from Germany. No interviewees from the first round participated in the second round. The interviews were conducted between Nov. 2016 and Jan. 2017. The average duration was 58 minutes. We recorded and transcribed all interviews.

The second-round interview began by asking the experts to describe the collaboration capabilities a health information system should have. Next, we presented the ten categories from the prior rounds, and asked the experts to evaluate whether, how, and why these categories of concerns were important to collaboration in healthcare. They were also asked whether the ten categories overlooked key concerns.

After 26 interviews, we reached conceptual saturation in the second round. We extracted, aggregated, and classified the concepts in the interview data, which validated the ten categories from the previous steps. Finally, we drew on the Six-Layer Model of Collaboration [19] to add an eleventh category of design concerns that are universal; relevant to all collaboration contexts. A full overview of interviewees and interview questions for both rounds are available on request.

Having synthesized the eleven categories, we returned to the literature and to the interview transcripts to extract a checklist of design questions for eliciting requirements related to each category of concerns. Each question relates to an issue that stakeholders and system designers should consider when designing a MO-MS collaboration system. 
Finally, to demonstrate how the general typology could be adapted to a specific MO-MS domain, we returned again to the concepts from the literature and the interviews. We elaborated the general typology with healthcare-specific elicitation prompts that could foster a more-thorough exploration of requirements for that domain. The next section presents the categories, with checklists of general design questions, and, where useful, prompts specific to healthcare.

\section{Research Results}

The first category (Category 0) addresses concerns common to all collaboration systems. These are not unique to the healthcare context, but are nonetheless essential to healthcare collaboration. We organize these concerns around the Six-Layer Model of Collaboration (SLMC) [19, 20]. The remaining ten categories (Category 1 to 10 ) elaborate Category 0 concepts with concerns that are specific to healthcare context. Category 0 therefore serves as the entry point for the rest of the categories.

Category 0: Collaboration Practices. The Collaboration Practices category addresses concerns that arise when individuals make a joint effort toward a group goal. The SLMC considers design concerns at six different levels of abstraction. The most-abstract is the Collaboration Goals Layer (1). A goal is a desired state or outcome. Concerns at this layer address the group goals, the stakeholders, and the private goals that motivate stakeholders to work toward the group goal. The Group Products Layer (2) concerns defining and designing the tangible artifacts or intangible states the group will work to create in order to achieve its group and private goals. The Group Activities Layer (3) concerns designing the work breakdown structure a group must do to create the group products. The Group Procedures Layer (4) concerns the design of techniques and tactics by which the stakeholders will move through each activity in the work breakdown structure. The Collaboration Tools Layer (5) considers the design and configuration of apparatus and technologies the group will use to execute its procedures. The Collaboration Behaviors Layer (6) concerns designing the constraints on what people should say and do with their tools to instantiate the procedures to move through the activities to create the deliverables to achieve their goals (for example, 'During the brainstorm, participants should not delete the contributions of others'). Category 0 proposes seven concrete design questions to remind stakeholders to reflect on concerns at all six layers of abstraction (See Table 1).

The Category 0 questions are prerequisites for the questions in the subsequent categories. Interviewee
\#45 (software provider for nursing work), said, for example: "Without ground rules and without a definition of collaboration tasks, it (collaboration in healthcare) will never work ... Before we start collaboration, our number one question is always whether all goals, rules, processes, activities, and so on have already been clearly defined."

Thus, we recognize the Category 0 concerns as meta-requirements for collaboration in healthcare.

Category 1: Role Variety. Role variety concerns the assortment of roles who must be involved in collaborative healthcare, the specific classes of events in which each role must participate, and the capabilities the system must afford to support their involvement in those events. A wide variety of stakeholders with differing interests and expertise must collaborate in healthcare.

This category of design concerns is often not thoroughly considered in health collaboration system designs. Our interviewees highlighted the patient role as a typical example, noting that systems often precluded their involvement. Interviewee \#26 (assistant ophthalmologist) for example, said: "Even for communication between doctors, I think it is important to involve patients. Because otherwise, for example, the information passed between physicians is just not accurate. It's second-hand."

In Category 1, our design questions (see Table 1) aim to identify roles, and role-based privileges and restrictions that should be offered by health information systems (e.g., role-based enforcement of privacy policies for patient records). Some of the questions are associated with options derived from the literature and the interviews.

Category 2: Service Perimeter. Service Perimeter concerns the variety of entities outside the organization. The findings suggest that, in some cases, a system should be able to accommodate entities in different geographical areas, with differing political conditions, and should accommodate participation by people from different industries because "People should try get rid of or blur differences [boundaries] that are in conjunction with laws, rules or culture stuff for different organizations" (Interviewee \#32, health IT developer). Collaboration in healthcare often occurs among different organizations across different boundaries, as explained by Interviewee \#36 (IT researcher): "I know someone who is a doctor [in Germany], but has patients in Dubai and Qatar ... He often works [in Germany] together with his patients there, and of course with their local hospitals. I believe the boundaries don't have to exist."

Design questions in Category 2 assist designers to identify and address these possible boundaries. 
Table 1. Design concerns and design questions for information systems that support collaboration in healthcare

\begin{tabular}{|c|c|c|}
\hline Category & Design Question [Aid in Answering the Question, if Applicable] & Related to \\
\hline \multirow{7}{*}{$\begin{array}{l}0 . \\
\text { Collaboration } \\
\text { Practices }\end{array}$} & Q0.1 What goals do collaborators seek to achieve? & SLMC * \\
\hline & Q0.2 What deliverables do collaborators need to achieve each goal? & SLMC* \\
\hline & Q0.3 What work packages must collaborators complete to create each deliverable? & SLMC* \\
\hline & Q0.4 What procedures must collaborators follow to complete each work package? & SLMC* \\
\hline & $\begin{array}{l}\text { Q0.5 What technological support will collaborators require to execute each } \\
\text { procedure? }\end{array}$ & SLMC * \\
\hline & Q0.6 What information and data do collaborators need to create each deliverable? & SLMC* \\
\hline & $\begin{array}{l}\text { Q0.7 What must collaborators say and do with the system affordances under what } \\
\text { constraints to instantiate each procedure? }\end{array}$ & SLMC* \\
\hline \multirow{6}{*}{$\begin{array}{l}\text { 1. Role } \\
\text { Variety }\end{array}$} & $\begin{array}{l}\text { Q1.1 What are the roles involved in the collaborative activities and what are their } \\
\text { interests/goals? [physicians; patients; patients' family members; friends; } \\
\text { anesthetists; nurses; midwives; pharmacists; radiologists; orderlies; health } \\
\text { workers; healthcare administration staff; researchers; insurance company staff; } \\
\text { government staff; other] }\end{array}$ & Q0.1 \\
\hline & $\begin{array}{l}\text { Q1.2 For each different role, what relevant events are there in the collaborative } \\
\text { process? [prevention (e.g. screening); propaedeutic, (e.g. vital signs) measurement; } \\
\text { diagnostic (e.g., medical imaging); therapeutic (e.g., chemotherapy); anesthesia } \\
\text { (e.g., local anesthesia); surgeries (minimally invasive procedures); nursing (e.g., } \\
\text { wound care); administration (e.g., insurance settlement); other] }\end{array}$ & Q0.3 \\
\hline & $\begin{array}{l}\text { Q1.3 For each event in the collaborative activities: what roles are allowed and not } \\
\text { allowed to participate in? }\end{array}$ & Q0.7 \\
\hline & $\begin{array}{l}\text { Q1.4 For each event in the collaborative activities: if a role is allowed to participate } \\
\text { in it, what actions are allowed and not allowed for this role? }\end{array}$ & Q0.7 \\
\hline & $\begin{array}{l}\text { Q1.5 For each event in the collaborative: if a role is allowed to participate in it, what } \\
\text { data access actions [view; add; edit; associate; judge, cut; copy; delete] for what } \\
\text { data are allowed for this role? }\end{array}$ & Q0.7 \\
\hline & $\begin{array}{l}\text { Q1.6 For each event in which a role is allowed to participate, what data and } \\
\text { information are preferred by this role, in what formats and in what media? }\end{array}$ & Q0.6 \\
\hline \multirow{4}{*}{$\begin{array}{l}\text { 2. Service } \\
\text { Perimeter }\end{array}$} & $\begin{array}{l}\text { Q2.1 What outside entities are involved in the collaborative activities, and what are } \\
\text { their interests/goals? [hospitals; clinics; laboratories; pharmacies; nursing homes; } \\
\text { funeral homes; social welfare departments; aid organizations; law departments; } \\
\text { healthcare authorities; insurance companies; research institutes; other] }\end{array}$ & Q0.1 \\
\hline & $\begin{array}{l}\text { Q2.2 What are the different legal requirements, specifications, or restrictions each } \\
\text { outside entity must follow based on geographical differences [city level; county } \\
\text { level; state level; country level; other]? }\end{array}$ & Q0.4 \\
\hline & $\begin{array}{l}\text { Q2.3 What are the different legal requirements, specifications, or restrictions each } \\
\text { outside entity has to follow concerning industry sector differences [healthcare; } \\
\text { pharmaceutical; education; financial services; public utilities; other]? }\end{array}$ & Q0.7 \\
\hline & $\begin{array}{l}\text { Q2.4 What differences of organizational, regional, and national culture must be } \\
\text { considered, to work with outside entities [distances; time differences; symbols; } \\
\text { language; norms; traditions; religions; workplace manners; other]? }\end{array}$ & Q0.4 \\
\hline \multirow{4}{*}{$\begin{array}{l}\text { 3. Response } \\
\text { Times }\end{array}$} & Q3.1 What is the response latency is allowed for each class of collaborative event? & Q0.4 \\
\hline & $\begin{array}{l}\text { Q3.2 What events should be conducted in in real-time (e.g., synchronous with vs. } \\
\text { coordinated with other actors or with other events)? }\end{array}$ & Q0.4 \\
\hline & Q3.3 In what situations can pre-defined event latency standards be allowed to vary? & Q0.4 \\
\hline & Q3.4 How should collaborators act if the pre-defined event latency cannot be hold? & Q0.7 \\
\hline \multirow{4}{*}{$\begin{array}{l}\text { 4. Device } \\
\text { Integration }\end{array}$} & $\begin{array}{l}\text { Q4.1 What kinds of user devices should be supported for accessing the system } \\
\text { [stationary devices; mobile devices; wearable devices; no-barrier devices; other]? }\end{array}$ & Q0.5 \\
\hline & Q4.2 To what devices should the system specifically adapt? & Q0.5 \\
\hline & Q4.3 What specific tasks in what situations should each class of devices support? & Q0.5 \\
\hline & $\begin{array}{l}\text { Q4.4 What data access actions [read; write; edit; copy; delete; other] in what } \\
\text { situations are allowed for each supported device? }\end{array}$ & Q0.5 \\
\hline \multicolumn{3}{|c|}{$\begin{array}{l}\text { Note: * Category } 0 \text { builds the idea of the Six-Layer Model of Collaboration (SLMC) by Briggs et al. [20]. Q0.1 } \\
\text { concerns the Collaboration Goals Layer, Q0.2 the Group Products Layer, Q0.3 the Group Activities Layer, Q0.4 } \\
\text { the Group Procedure Layer, Q0.5 and } 0.6 \text { the Collaboration Tools Layer, and Q0.7 the Collaborative Behaviors } \\
\text { Layer. Design questions in category } 1 \text { to } 10 \text { specify the idea related to the SLMC for healthcare settings. }\end{array}$} \\
\hline
\end{tabular}


Category 3: Response Times. Category 3 concerns the variety of events to which the health information system will respond, and the capabilities the health information system must afford to attain minimum necessary response times for each kind of organization that involved in a given collaboration, and the capabilities the system must afford to support their involvement.

Timeliness is one of the most critical indicators of success for collaboration in healthcare: "To do everything in a timely manner is the basis of collaboration in healthcare. ... Imagine you have

Table 1. Continued

\begin{tabular}{|c|c|c|}
\hline Category & Design Question [Aid in Answering the Question, if Applicable] & Related to \\
\hline \multirow{6}{*}{$\begin{array}{l}\text { 5. System } \\
\text { Inter- } \\
\text { operability }\end{array}$} & $\begin{array}{l}\text { Q5.1 What are the typical data that are needed for the collaborative activities } \\
\text { [electronic medical records; electronic health records; personal health records; } \\
\text { reference data from disease registries; clinical tries data; medication adherence } \\
\text { data; administrative data; claims data; health survey data; socioeconomic data } \\
\text { (about determinants of health)]? }\end{array}$ & Q0.6 \\
\hline & Q5.2 How do structures of the needed data look like? & $\mathrm{Q} 0.6$ \\
\hline & Q5.3 For a certain type of data, what are the major systems that create them? & $\mathrm{Q} 0.6$ \\
\hline & $\begin{array}{l}\text { Q5.4 How does the system use each type of data and what data access actions does } \\
\text { the system have to the data [read; write; edit; copy; delete]? }\end{array}$ & Q0.6 \\
\hline & $\begin{array}{l}\text { Q5.5 What are internal or external legacy approaches or tools, with which the } \\
\text { system needs to interoperate? }\end{array}$ & Q0.5 \\
\hline & Q5.6 How should the system interoperate with the legacy approaches or tools? & $\mathrm{Q} 0.5$ \\
\hline \multirow{5}{*}{$\begin{array}{l}\text { 6. Process } \\
\text { Adaptability }\end{array}$} & $\begin{array}{l}\text { Q6.1 Under what operative conditions does each work package in collaboration take } \\
\text { place [participants; necessary (medical) resources; medical observations; status of } \\
\text { other work packages]? }\end{array}$ & Q0.4 \\
\hline & $\begin{array}{l}\text { Q6.2 What operative conditions, under which a work package takes place, are likely } \\
\text { to change or adapt themselves or have exceptions? }\end{array}$ & Q0.4 \\
\hline & $\begin{array}{l}\text { Q6.3 For the operative conditions that are likely to change or have exceptions, how } \\
\text { should changes or exceptions be supported by the system? }\end{array}$ & Q0.4 \\
\hline & $\begin{array}{l}\text { Q6.4 What legal requirements, specifications, or restrictions under which } \\
\text { collaboration takes place, are likely to change or adapt themselves? }\end{array}$ & Q0.4 \\
\hline & $\begin{array}{l}\text { Q6.5 For the legal requirements, specifications, or restrictions that are likely to } \\
\text { change, how should changes or adaptions supported by the system? }\end{array}$ & Q0.4 \\
\hline \multirow{3}{*}{$\begin{array}{l}\text { 7. User } \\
\text { Awareness }\end{array}$} & $\begin{array}{l}\text { Q7.1 What are the defined goals, rules, individual responsibilities, and available } \\
\text { resources for each work stage that should be used to inform collaborators? }\end{array}$ & Q0.3 \\
\hline & $\begin{array}{l}\text { Q7.2 What kinds of information is needed by collaborators to know the completion } \\
\text { progress of deliverables in each work package [starting time; utilization of } \\
\text { resources; current location; schedule adherence; } \text { expected finish time]? }\end{array}$ & Q0.2 \\
\hline & $\begin{array}{l}\text { Q7.3 What information is needed by a collaborator to know with whom she or he is } \\
\text { collaborating and current states of other collaborators' actions? }\end{array}$ & Q0.7 \\
\hline \multirow{4}{*}{$\begin{array}{l}\text { 8. (Patient) } \\
\text { Data } \\
\text { Integration }\end{array}$} & $\begin{array}{l}\text { Q8.1 What internal and external (patient) data are at least required for collaborative } \\
\text { health care that is supported by the system? }\end{array}$ & Q0.6 \\
\hline & Q8.2 How can the system access or collect the needed (patient) data? & Q0.6 \\
\hline & Q8.3 What needed (patient) data can be produced by the system? & $\mathrm{Q} 0.2$ \\
\hline & $\begin{array}{l}\text { Q8.4 How are (patient) data produced by system that support future collaborative } \\
\text { activities stored and/or updated by the system? }\end{array}$ & Q0.2 \\
\hline \multirow{2}{*}{$\begin{array}{l}\text { 9. Richness } \\
\text { of System } \\
\text { Cues }\end{array}$} & $\begin{array}{l}\text { Q9.1 For each kind of information and data in the system, which human senses can } \\
\text { be used to increase collaborators' perceived richness when processing data [sight; } \\
\text { hearing; taste; smell; touch; balance; acceleration; temperature; proprioception; } \\
\text { pain; emotion; further internal senses]? }\end{array}$ & Q0.6 \\
\hline & $\begin{array}{l}\text { Q9.2 For each kind of data or information, what content forms can increase its } \\
\text { richness perceived by collaborators [texts; images; animations; videos without } \\
\text { sounds; videos with sounds; } 3 \text { D contents; virtual reality contents; digital games; } \\
\text { stimulations]? }\end{array}$ & Q0.6 \\
\hline \multirow{4}{*}{$\begin{array}{l}\text { 10. Concept } \\
\text { Clarity }\end{array}$} & $\begin{array}{l}\text { Q10.1 What concepts, statements, or (medical) values in the collaboration process } \\
\text { need definitions or clarifications, or are subject to interpretations? }\end{array}$ & Q0.6 \\
\hline & $\begin{array}{l}\text { Q10.2 What concepts, statements, or (medical) values that are produced by the } \\
\text { system need definitions, clarifications or interpretations (also for possible future } \\
\text { collaborative activities)? }\end{array}$ & Q0.2 \\
\hline & $\begin{array}{l}\text { Q10.3 What are the target user groups for the definitions or interpretations of each } \\
\text { (medical) concept or value? }\end{array}$ & Q0.1 \\
\hline & $\begin{array}{l}\text { Q10.4 How should the concepts, statements, or values be defined, clarified, or } \\
\text { interpreted for each different target user group [using semantic standards (e.g. } \\
\text { nomenclatures); using professional languages; using daily languages]? }\end{array}$ & Q0.6 \\
\hline
\end{tabular}


something like WhatsApp in healthcare: Where is the value if you get your message on the next day? Why don't we go back to the age with post?" (Interviewee \#34, associate chief neurologist).

Interviewees suggested that prompt responses in a health information system would reduce the cognitive load associated with unnecessary wait times. For example, Interviewee \#46 (registered nurse) told us: "I followed the instructions in our system for our [collaboration] process. If there is a delay because of the system, then I have to wait, and then the next colleague has to wait, and then the whole team. It's annoying. ... It's always beneficial if everything can be assigned as soon as possible so that we don't have to waste our valuable time or make compromises just because of the IT system. "Interviewees stressed that collaborative activities that are often based on exchange of data should even always be as close to real-time as possible (i.e., the quicker the better). Interviewee \#48 (head of a health IT consultancy) said: "As a whole, it [data exchange] is interlocking. Data go through the whole chain. The data you need right now might depend on the [availability of] data from earlier steps or other collaborators. So the truth is that we always have to keep data exchange in realtime because the data might actually be needed in the next emergency situation."

This category offers four questions to probe for concerns about system response times.

Category 4: Device Integration. This category concerns the variety of data-active devices that simplify collaborative activities (e.g., wearable sensors; smartphones; tablets; non-barrier devices), and the capabilities the system must afford to accommodate their use. Device Integration gives health IT users ubiquitous collaboration capabilities, as explained by Interviewee \#34 (associate chief neurologist): "I am usually involved in several medical cases at the same time. ... Our system was on my PC before. Then I had to go back to my office to check the system so that I would not miss states or instructions. I went to ward or emergency room, and then turned back to check my PC, again and again. ... Now that they gave me an iPad, its better, but still annoying, because I now have to carry so many things: medical devices, paper stuff, and so on. ... I told my hospital, I need a smart watch."

Moreover, Device Integration allows health IT users to collaborate in an unobtrusive manner (e.g., data collection through wearable sensors instead of manual measuring or entering), as described by Interviewee \#44 (health IT engineer): "I see this as the future [of collaboration] from a data perspective. Because it's not just about an unobtrusive way to use IT, but also about giving people the possibility to automatically bring their own data into healthcare with sensors anytime, anywhere, without using cables. Such data are even more important than what you can collect in hospitals. ... Even at home we would have Wi-Fi to enable our patients to upload their daily data to a server or data center by using sensors, which was impossible or unimaginable before."

This category contains four design questions that focus on enabling both manners with user devices.

Category 5: System Interoperability. Category 5 concerns the variety of internal and external information systems with which the collaboration system must interact at the time it is deployed and in the future, and the capabilities that the system must afford to accommodate those interactions. This category focuses designers on the capability of health information systems to interoperate with heterogeneous digital medical systems that are not necessarily built to common standards. Interviewee \#38 (health IT researcher) said: "In a perfect world, we would use the same standards everywhere [in healthcare], and people wouldn't have to worry about the interoperability problem, because we would always have a standard. ... In the real world different [healthcare] systems have different ways to exchange, which means you should also take those non-standard systems into consideration."

We found that health information systems also have to pay attention to legacy tools or systems, including non-computerized paper-based tools. In healthcare, legacy tools in collaborative activities are still common, and cannot easily be replaced, as, for example, the story of Interviewee \#37 (registered nurse): "Our team also uses tools we invented ourselves. ... For the patient assignment, we use a whiteboard in our office. We just write down the names there, although we already have an IT system for that. It is because that our team leader is an old lady who learned the white-board approach from her leader, I don't know, 30 years ago. And she said, it's a best practice ... Once I asked my friend from another hospital; they have a similar situation! ... So, my point is that you just cannot ignore traditional tools. They have become integral part of our (collaboration) work."

Design questions that belong to this category help designers identify system requirements that are relevant for system's interoperation with heterogeneous systems and different approaches.

Category 6: Process Adaptability. Process Adaptability concerns the variety of conditions under which people must collaborate to provide healthcare, and the capabilities the system must afford to accommodate that range of conditions. This category is relevant for two reasons. First, although the 
healthcare industry strives to define all conditions or situations for collaboration in an exhaustive manner, unpredictable occurrences and exceptions often appear (e.g., new variant of a certain disease/symptom for which pre-defined collaborative treatment process is not appropriate). Interviewee \#30 (obstetrician) stated: "People think that healthcare processes are very well defined, but it's not really the case because it's too difficult to completely define all of them ... Everyone thinks that we have already defined all possible situations clearly ... they think that no matter what happens, there will always be a solution, a path for it. But it's not hundred percent. There are always exceptions that we never met before. So, IT is still not flexible enough, at least from the medical perspective. ... It would be great if we can adjust the [collaboration] process a little bit on-the-fly."

Second, even small adaptions of organizational policy or industrial regulations can affect the ways people collaborate in healthcare. Interviewee \#37 (registered nurse) told us: "Next year, we will change from four levels to five levels of nurses, because insurance companies want it. So, we have to reorganize some [collaboration] processes, which already happened last year."

Interviewee \#48 (head of a health IT consultancy) also stated: "In the U.S., for example, you had Obama Care, then something (about the collaboration process) has to change. Several years later, the next president wants to eliminate it, and something (about the collaboration process) will have to change again."

By proposing five design questions in Table 1, Category 6 highlight relevant requirements that enable systems to adapt to changes or exceptions in collaboration in healthcare.

Category 7: User Awareness. User Awareness concerns the degree to which users can know: a) with whom they are collaborating (identities and roles); b) what each person is expected to do (rules about what each role should do under what constraints using what capabilities); c) what aspect of the system each person is currently in; d) what each person is doing; e) who executed each action; f) the current states of activities; and g) the current states of the environment. This category not only aims at increasing a collaborator's understanding of his/her own role, rules, tasks, and responsibilities, but also at increasing collaborator's cognitive transparency of the whole collaboration environment. Interviewee \#27 (gynecologist) stated: "When a patient is in our hospital, what stage he is currently in is very, very important for the next department that will receive him to know these things ... for example, to manage the bed situation, availability of doctors and nurses, and so on. This would provide buffer time for us, and increase the efficiency of coordinating the team."

Interviewees further argued that increased transparency improves collaboration in healthcare from the medical data perspective: "There is an IT platform for patient data exchange in Austria; it is a centralized electronic patient record system. ... The patient has to define and decide, what doctors have what kinds of access to what part of my data. The data will not only be shared, but also be withdrawn, if something changes. Of course, we are also talking a bit about the topic data privacy, but I see this topic more as transparency. And I believe that transparency has to be the pre-condition if data exchange can be realized at all in healthcare. So, we have to use a high art to design our system so that it can support this transparency. ... Increasing user awareness could act as such a high art to dynamically inform users about everything in their environment that is important to them, and to calm them down. ... This is a kind of guarantee that the whole [collaboration] based on data exchange would work." (Interviewee \#48, head of a health IT consultancy).

Design questions in this category especially focus on what different (kinds of) information is (are) needed to increase User Awareness.

Category 8: (Patient) Data Integration. This category concerns the variety of sources from which the most relevant data for collaboration in healthcare must be gathered, the completeness of data, and the capabilities the system must afford to integrate those sources. In healthcare, patient data are the most essential data for collaborative activities. Patient data are often decentralized and fragmented, and have therefore sometimes limited availability (e.g., [21]). Interviewee \#38 (health IT researcher) stated: "Without patient data, cooperation in healthcare, which is always about patients, is impossible or limited". Interviewee \#33 (ophthalmologist) explained that: "It's always necessary to collect all relevant data about a patient ... I am an eye doctor but I also want to know about patient's other detailed information, like when was her last period or has the patient ever paid for sex. ... Patient data are often not complete. Maybe they have been collected, but I don't know where they are. So, I have to collect them again ... In the end, data are description of a patient, like a specification or manual for him: the more detailed the better. Also, if I transfer data to another doctor, I am sure he prefers the detailed manual, not just a part of it”. Design questions in Category 8 aim to identify relevant system requirements that increase the completeness of patient.

Category 9: Richness of System Cues. Category 9 concerns the variety of media richness associated 
with the information cues the system provides to users (e.g., explanations, patient records, human communication), and the capabilities the system must afford to present that variety. This category suggests designers to leverage media richness to help users understand (medical) data during collaboration in healthcare in a more effective manner and reduce users' cognitive load. This is because abstract information and/or data exist in healthcare that can be hard to interpret without assistance. Interviewee \#42 (principal director of health IT consulting) gave an example: "My mother is 82 years old and she went to see doctor. It took two hours for the doctor to finally understand where the problem was. So, this is actually one of the biggest challenges in healthcare collaboration. ... Without using, for example, video technologies, it is difficult to use normal language to express everything. ... let's be more innovative, you can build a model of human body, with which you can show where exactly the problem is or simulate what movement would cause what hurt. ... It's much more intuitive than organizing language, and for understanding also, because you can just show it."

Interviewee \#31 (orthopedist in charge) explained how media richness could help collaborators reduce their cognitive load: "Pictures and texts are not enough. Before, we had to use a series of pictures for the movement of a joint, for example. It was like you read these pictures and used your brain to image the movement, like lantern slides. It was tiring. ... I also had to use text to describe everything to let others know what I did and found, which took a lot of time and nerves. ... Now, you can shoot videos or create animation stead of writing text description. People can see what it actually was. It's straightforward."

Design questions in this category do not only address what forms of information/data can be applied but also what human senses should be used to increase Richness of System Cues.

Category 10: Concept Clarity. Concept Clarity concerns the variety of concepts - medical and otherwise - that people must understand for successful collaboration in healthcare, and the capabilities the system must afford to assure that people gain shared understanding of those concepts. As pointed out by the interviewees, collaborators in healthcare do not necessarily possess sufficient knowledge that enable them to fully understand medical information or data (e.g., patients). Even for collaborators with medical background, assistance by the system can help them understand external information or data more precisely and thereby avoid misunderstanding. For example, Interviewee \#27 (gynecologist) stated: "In healthcare, data are sometimes not easy to understand because there are too many different organizations.
Different hospitals could have different interpretations of the same concept. That's why we do not really take over all information for certain [medical examination] items, because some other small hospitals have their own interpretation, which is totally wrong. ... I also had a patient who did some examinations in a foreign country. ... People there used [English] abbreviations that I never saw, and I had to guess. ... Sometimes also for a doctor from another area, he would not understand terms in my data or the meaning of them. I think you should try to describe or specify your data to the greatest extent so that people will have a consistent understanding."

Design questions in this category assist designers to identify what information/data, and how they should be defined or clarified for collaborators.

\section{Discussion}

\subsection{Implications}

The typology of categories and design questions can be used to direct stakeholder attention to MO-MS collaboration-related requirements that they might otherwise overlook. Category 0, however, is a metacategory; the other ten categories elaborate one or more of the Category 0 concerns. The last column of Table 1 links the design questions from Categories 1 to 10 to the universal design concerns in Category 0. For example, Q3.4 (i.e., 'How should collaborators act if the prescribed minimum event latency cannot be maintained?') is associated with Q0.7 (i.e. 'What must collaborators say and do with the affordances to instantiate each procedure?'). Design question Q3.4 both addresses a specific topic for IT-supported MOMS collaboration (i.e., Response Time) but is rooted in the more general SLMC (i.e., through Q0.7).

Based on these relationships, we recommend system designers to apply the proposed design concerns and design questions in two different manners. System designers who aim to implement a new system that supports MO-MS collaboration could start with design questions in Category 0 that represents the more general SLMC. For each design question enumerated in Category 0, system designers can further investigate its related design questions in Category 1 to 10 (e.g., for Q0.1: Q1.1, Q2.1, and Q10.3) to get a more deepened and specified understanding of this design question coming from Category 0. Because SLMC provides a holistic view on designing collaboration systems, system designers are thereby able to address related system requirements for collaboration in healthcare in a holistic manner. For system designers who aim to improve an existing system concerning a certain 
aspect, we suggest them to start with the proposed Category 1 to 10. System designers can use the proposed categories as a checklist to first identify the aspects they want to target. By doing so, system designers can identify requirements that are relevant for the identified aspects in a more efficient manner.

\subsection{Contributions}

4.2.1. Contributions to health IT. For the domain of health IT, this study contributes to an improved understanding of the topic of collaboration in healthcare. Previous studies stress the need to conceptualize healthcare collaboration that can be supported by IT, and regard this as a perquisite for facilitating related studies in healthcare (see [6]). This paper is among the first to address this need. The proposed categories of design concerns highlight specific aspects that are relevant to designing health information systems to support collaboration in a holistic manner. The suggested checklist of design questions adds specifics to the categories. Moreover, where applicable, we offer a set of possible answers to the questions. Collectively, the proposed categories, design questions, and possible answers deepen our understanding of the problem space and also solution space for IT-supported collaboration in healthcare. Separately, each category, with its design questions and possible answers, serves as a cornerstone for future health IT research, e.g., starting from category 7 (User Awareness), researchers can investigate the approaches and forms of information related to increased user awareness during collaborative healthcare activities.

\subsubsection{Contributions to Collaboration Engineering.} Although we drew insights from healthcare collaboration, this study contributes knowledge on general large-scale IT-supported MO-MS collaboration, of which healthcare is a representative instance. The eleven general categories of design concerns are common to all large-scale MO-MS collaboration. The design questions and their possible answers generalize this significance. For example, Q2.4 highlights specific concerns of different culture elements, including language, time differences, norms and traditions, caused by wide perimeter (i.e., category 2) of large-scale MO-MS collaboration processes that are not always self-evident in more small-scale collaborations. In a similar manner, Q8.1 highlights the necessity to take diverse different internal as well as external sources for data integration (i.e., category 8) into specific consideration, which is also a consequence of a large-scale MO-MS collaboration usually with a high number of information sources.
The design concerns we discovered in the healthcare context should generalize to any MO-MS context. Further, we undertook this research to discover design concerns that were not self-evident from research on smaller-team collaboration. It appears, though, that, under some conditions, these concerns would also be useful for designing process support applications for smaller teams. Thus, this study fulfills the purpose of Design Science Research, which is to use scientific knowledge and methods to solving important classes of practical problems in the field, and to contribute back new knowledge [22].

\subsection{Limitations and Future Research}

This research examined design concerns for MOMS collaboration only in the context of collaborative healthcare. It may be possible to discover additional design concerns and or additional design questions by exploring MO-MS in other high-stakes domains.

This study only examined MO-MS collaboration in Germany and China. More may be learned with explorations in other countries. This study also focused only on professional stakeholders - IT and healthcare experts. It could be useful to explore further with stakeholders who are not healthcare and IT professionals, e.g., insurance companies, patients, and their families.

It may also be useful to focus future research on exploring the relationships among the 11 categories of design concerns and the three core collaboration needs identified in the healthcare literature. For example, some interviewees mentioned that overemphasis on certain categories could lead to unexpected distractions that impede collaborative activities- For example, when discussing 'Concept Clarity' (Category 10) in the context of communication support (Need 3), interviewee \#48 (head of health IT consultancy) pointed out that "sometimes using terminology or explanation could make collaboration in healthcare more difficult. [...] people have to communicate with each other intensively, like in emergency cases. [...] If the (IT) system adds additional explanations to medical terms, the participants (collaborators) could feel overwhelmed." Exploring such relationships may further deepen conceptual understandings of the categories of concerns, and of the problem space.

\section{Conclusion}

With this literature review and Exploratory study, we investigated design concerns pertaining to largescale IT-supported MO-MS collaboration. We derived a typology of design concerns and design questions 
that should be useful for improving MO-MS collaboration systems designs. We demonstrated that the generalizable typology could be elaborated with details to extend its utility in a specific MO-MS domain, in this case, healthcare, to foster morecomplete requirements definition for new collaboration systems in that domain.

\section{References}

[1]https://esa.un.org/unpd/wpp/Publications/Files /WPP2017_KeyFindings.pdf, 2017.

[2]Dieleman, J., T. Templin, N. Sadat, ... and C. Kurowski, "National spending on health by source for 184 countries between 2013 and 2040", The Lancet, 387(10037), 2016, pp.2521-2535.

[3] Dehling T., F. Gao, S. Schneider, and A. Sunyaev, "Exploring the far side of mobile health: Information security and privacy of mobile health apps on iOS and Android", JMIR Mhealth Uhealth, 3(1), 2015, p. e8. [4]World Health Organization, " Medicines shortage: global approaches to addressing shortages of essential medicines in health systems", WHO Drug Information, 30(2), 2016.

[5]Taplin, S., S. Weaver, V. Chollette, L. Marks, ... and E. Salas, "Teams and teamwork during a cancer diagnosis: Interdependency within and between teams", Journal of oncology practice, 11(3), 2015, pp.231-238.

[6]Eikey, E., M. Reddy, and C. Kuziemsky, "Examining the role of Collaboration in studies of health information technologies in biomedical informatics: a systematic review of 25 years of research", Journal of biomedical informatics, 57, 2015, pp.263-277.

[7]Ratnam, K., Dominic, P., and T. Ramayah, "A structural equation modeling approach for the adoption of cloud computing to enhance the Malaysian healthcare sector", Journal of medical systems, 38(8), 2014, p.82.

[8]Alsos, O., A. Das, and D. Svanæs, "Mobile health IT: the effect of user interface and form factor on doctor-patient communication", International journal of medical informatics, 81(1), 2012, pp.12-28.

[9]Mirbaha, F., G. Shalviri, B. Yazdizadeh, K. Gholami, and R. Majdzadeh, "Perceived barriers to reporting adverse drug events in hospitals: A qualitative study using theoretical domains framework approach", Implementation science, 10(1), 2015, p. 110 .

[10]McKinlay, E. and S. Pullon, "Having interprofessional education during the undergraduate years is essential for building teamwork skills in general practice: Yes", Journal of primary health care, 6(4), 2014, pp.331-333.
[11]Tricco, A., J. Antony, N. Ivers, ... and S. Straus, "Effectiveness of quality improvement strategies for coordination of care to reduce use of health care services: a systematic review and meta-analysis", Canadian medical association journal, 186(15), 2014, pp.E568-E578.

[12]Gao, F., S. Thiebes, and A. Sunyaev, "Exploring cloudy collaboration in healthcare: An evaluation framework of cloud computing services for hospitals". In 49th Hawaii International Conference on System Sciences (HICSS), 2016, pp. 979-988.

[13]Rudin, R. and D. Bates, "Let the left hand know what the right is doing: a vision for care coordination and electronic health records", Journal of the American Medical Informatics Association, 21(1), 2014, pp.13-16.

[14]Ahlfeldt, R., A. Persson, H. Rexhepi, and K. Wahlander, "Supporting active patient and health care collaboration: A prototype for future health care information systems", Health informatics journal, 22(4), 2016, pp.839-853.

[15]Stebbins, R., Exploratory research in the social sciences, Sage, Thousand Oaks, 2001.

[16]http://markets.businessinsider.com/news/stocks/it -outsourcing-by-hospitals-and-medical-groups-

continues-to-boom-fewer-vendors-meeting-

expectations-1002652271, 2017.

[17]http://www.ingrammicroadvisor.com/datacenter/top-data-center-trends-in-healthcare, 2018.

[18]Gao, F., S. Thiebes, and A. Sunyaev, "Rethinking the meaning of cloud computing for healthcare: A taxonomic perspective and future research directions", Journal of medical Internet research, 20(7), 2018, p. e10041.

[19]de Vreede, G., R. Briggs, and A. Massey, " Collaboration Engineering: foundations and opportunities", Journal of the Association of Information Systems, 10(3), 2009, pp. 121-137.

[20]Briggs, R., G. Kolfschoten, G. Vreede, C. Albrecht, D. Dean, and S. Lukosch, "A Six-Layer Model of Collaboration for Designers of Collaboration Systems", in Advances in collaboration systems, pp. 211-228.

[21]Otte-Trojel, T., A. de Bont, M. Aspria, S. Adams, T. Rundall, J. van de Klundert, and M. de Mul, "Developing patient portals in a fragmented healthcare system", International journal of medical informatics, 84(10), 2015, pp.835-846.

[22]Briggs, R. and G. Schwabe, "On expanding the scope of design science in IS research", in Serviceoriented perspectives in design science research, pp.92-106.

[23]Benlian, A., W. Kettinger, A. Sunyaev, and T. Winkler, "The transformative value of cloud computing: A decoupling, platformization, and recombination theoretical framework", Journal of management information systems, 35 (3), 2018. 